\title{
Uma proposta para (re)significar a avaliação na formação de professores
}

\section{A proposal to (re) define the valuation in teacher's formation}

\author{
Cátia Zílio \\ Especialista em Tutoria em EAD, Universidade Federal do Rio Grande do Sul, Brasil \\ e-mail: catitatpq@gmail.com
}

RESUMO: Este artigo apresenta um estudo sobre a avaliação, enquanto processo dialógico e formativo no contexto de um Curso de Licenciatura em Pedagogia, na modalidade a Distância. Foi produzido a partir da construção dos Portfólios de Aprendizagens e da análise das produções de alunas, acompanhadas das intervenções da tutoria e das relações desencadeadas por essas. Foi possível concluir sobre a importância de um processo avaliativo que contemple a unicidade entre teoria e prática na formação de professores da Educação Básica.

Palavras-chave: Avaliação, formação de professores, Educação a Distância, portfólio de aprendizagens

ABSTRACT: This article presents a study about the valuation as a dialogic process and formative in the context of a Bachelor of Pedagogy at Distance mode. It was produced from the construction of the Learning Portfolio and analysis of students' productions, accompanied by tutors intervention and the relations triggered by them. It was able to conclude about the importance of a valuation process that contemplates the unicity between theory and practice in training teachers of basic education.

Keywords: valuation, teacher's formation, distance education, Learning Portfolio

\section{Contexto do estudo}

Este artigo apresenta uma análise sobre a experiência de construção dos portfólios de aprendizagens ao longo de um Curso de Licenciatura em Pedagogia na modalidade a Distância, aqui denominados blogs-portfólio. A utilização dos portfólios de aprendizagem fundamentou-se na necessidade de articular a teoria e a prática da avaliação. Acredita-se que essa proposta possibilita vivenciar práticas avaliativas que promovem a aprendizagem e podem ser transportas para a prática docente das alunasprofessoras. Segundo Villas Boas (2003, p.120):

\footnotetext{
A preparação para a avaliação tem sido um saber marginalizado na formação de professores. $\mathrm{O}$ uso do portfólio pode ser uma forma de colocá-lo em debate justamente em um dos espaços a ela destinados, o da formação de professores. Isto requer uma mudança de concepção de avaliação: o professor deixa de ser o "examinador" e o aluno o "examinado". Atua-se em parceria, sem com isso perder-se o rigor e a seriedade que a atividade impõe.
}

O contexto deste estudo terá como foco os registros das alunas vinculadas a um dos polos de apoio presencial do curso. A partir da análise das relações entre as produções das alunas em seus blogs-portfólio, as intervenções e os diálogos 
desencadeados por estas, busca-se compreender os processos de construção de um novo paradigma de avaliação. Concordamos com Santos (2003) que a avaliação deve ser concebida de forma constante e inclusiva e, portanto, não está centrada na função examinadora do professor. Neste sentido a construção dos blogs-portfólio não representa mera transferência da responsabilidade do professor para as alunas, mas propõe-se a incluir a autonomia e a autoria necessárias para a efetiva aprendizagem.

\section{Uma proposta pedagógica para a formação de professores}

Criado a partir das legislações educacionais que preveem a formação continuada dos professores da Educação básica, o planejamento do curso teve como principal preocupação o desenvolvimento de uma proposta administrativa e pedagógica flexível, sensível às particularidades das alunas que são, ao mesmo tempo, alunas e professoras. Em consonância ao projeto ao qual está vinculado, partiu-se das ações pedagógicas desenvolvidas pelas alunas-professoras em seus espaços de trabalho para a construção de instrumentos de reflexão, de tal forma que sua experiência cotidiana fosse enriquecida pelas bases teóricas.

Com duração de nove semestres, o curso foi pensado dentro de uma concepção interdisciplinar, materializada nas ações do grupo constituído pela coordenação geral do curso, coordenadores de pólo, coordenadores de cada interdisciplina, professores, tutores de sede (à distância) e tutores de pólo (presenciais). Sua organização curricular previu, a cada semestre, o desenvolvimento de Seminários Integradores que agregam e articulam as demais interdisciplinas do semestre às teorias, tecnologias e práticas pedagógicas. Sua principal característica é a flexibilização programática que articula as particularidades teóricas e metodológicas das diferentes áreas e enfoques temáticos, e também atender as necessidades e especificidades de cada eixo e pólo.

\section{Por que usar blogs como suporte para os portfólios?}

O desenvolvimento acelerado das TICs, que dinamiza os diferentes processos de construção do conhecimento, reivindica novos ambientes de aprendizagem baseados em concepções pedagógicas e metodologias que reconheçam a multidimensionalidade dos indivíduos, sejam eles presenciais ou virtuais. Segundo Nevado, Carvalho e Menezes (2007, p. 29), "as perspectivas de mudança não residem apenas na disponibilização de suportes tecnológicos potentes, mas em novas formas de conceber e praticar a educação". A principal inquietação desta proposta de formação de professores, residiu na articulação entre o domínio dos aparatos tecnológicos com a concepção pedagógica construtivista, na qual alunas, professores e tutores se inter-relacionam ativamente na construção, tensionamento e reconstrução do conhecimento, aqui entendido como provisório e inacabado.

É importante destacar que a legislação vigente, relacionada à formação de professores da Educação Básica, conforme Parecer CNE/CP 9/2001 e Resolução $\mathrm{CNE} / \mathrm{CP} 1 / 2002$, tem como princípio orientador o conceito de simetria invertida, ou seja, deve haver coerência entre a formação e a prática que se espera deste enquanto professor. Neste sentido, buscou-se capacitar para a integração das TICs às práticas pedagógicas das alunas, que são professoras dos Anos Iniciais da Educação Básica. Foi provocada uma ruptura com a ideia de que a inclusão digital restringe-se à disponibilização e ao acesso de hardware e softwares, transformando e qualificando os 
sistemas sociais e humanos que promovem a inclusão social mediada pelo uso contextualizado e significativo das TICs. Segundo Mark Warschauer (2006, p. 54; 57):

\footnotetext{
O modo mais simples, mas talvez o mais limitado, de considerar o acesso à TIC é por meio da posse de um equipamento. (...) Sem dúvida, a posse de um equipamento faz parte do acesso à TIC; no entanto, isso não constitui em si um acesso completo, o qual, nos tempos atuais, requer conexão à internet, assim como habilidades e entendimento para utilizar o computador e a internet de modo socialmente válido. (...)

O que está em jogo não é o acesso à TIC no sentido restrito de haver um computador no local, mas sim o acesso no sentido mais amplo da capacidade de utilizar a TIC para finalidades pessoal ou socialmente significativas.
}

Contudo, a restrição da utilização do ambiente virtual oficial da Universidade impossibilita a experimentação e vivência de propostas que poderiam ser facilmente transpostas para salas de aula das alunas. A solução encontrada foi a integração de outros espaços da web ao ambiente do curso, cujos critérios de escolha baseiam-se na facilidade de utilização, em termos de domínio das ferramentas tecnológicas e na viabilidade na comunicação e construção de redes de aprendizagens, baseadas na interação entre professores, tutores, colegas e web.

Outro elemento importante nesta escolha foi a universalidade do acesso, em termos de disponibilidade e gratuidade no cadastro. A utilização de Ambientes Virtuais de Aprendizagem, tal como o utilizado no curso, requer a vinculação a uma Instituição com disponibilidade de um servidor que permite a criação de turma e o armazenamento dos dados e informações trocados nas diversas ferramentas disponibilizadas pelo mesmo.

De forma a facilitar o trabalho cooperativo e o desenvolvimento da autoria e da autonomia optou-se pela utilização dos blogs. Segundo Zílio (2006, p. 4) "Blog é uma página na Internet, fácil de editar, publicar e atualizar, e tudo isto se faz sem as complicações ou as programações necessárias para a publicação de uma página. Nele qualquer pessoa com um e-mail, portadora de senha ou não, pode expor suas idéias, [...] qualquer lugar do planeta.". No caso específico deste curso, utilizamos o serviço atualmente oferecido pelo Google (www.blogger.com) que compreende o serviço de publicação e de hospedagem na web, além de contar com diversos recursos que facilitam a interação e a integração de diferentes recursos multimídia, tais como vídeos, fotos, música, entre outros. Além disso, foi criada e disponibilizada uma lista com os endereços dos blogs-portfólio de cada pólo em uma página do pbworks, de forma a agilizar o aceso e a navegação de tutores, colegas e professores.

\section{A interdisciplinaridade nos portfólios de aprendizagem}

Considerando a necessidade de aliar as teorias e práticas, é fundamental desenvolver um processo de avaliação condizente com essa concepção de Educação. Se o conhecimento não é um produto fixo e acabado, a avaliação deve oportunizar, dinâmica e continuamente, a ação-reflexão sobre as aprendizagens e a prática docente.

Dessa forma, o trabalho com portfólios significa um encontro com o novo, exigindo apreensão de seus significados e ruptura com práticas conservadoras menos dialógicas. Segundo Carvalho e Porto (2005), mais do que um mero documento ou instrumento de avaliação, os portfólios de aprendizagem oportunizam às alunas vivenciar reflexivamente o próprio processo de formação, permitindo identificar dificuldades, necessidades e concepções que a compõem. "Espera-se, com isto, que 
cada um assuma sua auto-educação, desenvolvendo espírito crítico e autônomo no seu encaminhamento" (CARVALHO e PORTO, 2005, p. 61).

O Eixo III do curso foi um momento importante para o aprofundamento e exploração das potencialidades do blog enquanto espaço de registro e reflexão. Não bastava utilizá-lo como mero repositório de informações, era fundamental interagir com outros espaços da web. Neste contexto, tutores e professores buscavam estimular as trocas entre colegas nos blogs através de proposições tais como: sugerir a visita ao blog de uma colega que tratasse de questões semelhantes; auxiliar na criação de links entre as postagens; orientar na criação de marcadores para classificar e agrupar as postagens, buscando propiciar o desenvolvimento e ampliação das redes de aprendizagem. Cabe destacar que a construção dos blogs-portfólios é um fazer constante, que, segundo Cecília Warschauer (1993, p. 62),

ajuda a construir a memória compreensiva, que é diferente daquela repetitiva e mecânica. Ela não é só uma recordação do aprendido, mas um ponto de partida para realizar novas aprendizagens. (...) Assim, o Diário é também um instrumento que vai alimentando a ligação entre teoria e prática.

A construção dos portfólios de aprendizagem foi coordenada e acompanhada, principalmente pela equipe de Seminário Integrador. Esta previa a realização de registros semanais, nos quais deveriam ser apresentadas as aprendizagens daquele período, acompanhadas das evidências e argumentos que as caracterizam como tal. Como atividade disparadora, foi proposta a análise do filme 'Onze homens e uma sentença', do qual desencadearam as discussões e conceitualização de evidências e argumentos. A proposta de registro nos blogs-portfólio é orientada de modo que os professores de Seminário Integrador constroem a proposta da tarefa que contemple a reflexão sobre as atividades realizadas pelas demais interdisciplinas do semestre em relação às aprendizagens das alunas e a prática docente que exercem em seus locais de trabalho. A freqüência dos registros deve ser quinzenal, no caso especifico do pólo abordado neste estudo.

No processo de acompanhamento das aprendizagens das alunas são utilizados como instrumentos avaliativos os comentários realizados pelos tutores de Seminário Integrador e eventualmente pelos professores. A partir dos mesmos são levantadas as questões mais recorrentes evidenciadas nos registros das alunas, objetivando problematizar, mediar a reflexão teórico-prática e instigar seu aprofundamento e continuidade. Para exemplificar destaco dois comentários realizados pela tutoria nas postagens de uma das alunas consideradas nesta pesquisa:

Podes qualificar mais esta postagem com mais detalhes sobre tua proposta e
tua reflexão sobre ela:
* por que foi uma atividade tumultuada?
* como foi a tua postura durante a proposta?
Em síntese: o que você aprendeu ao ensinar o que eram gráficos para os teus
alunos?
Lembre-se que diferente das reflexões semanais postadas no Pbworks, os
registros do blog-porfólio de aprendizagem deve priorizar a reflexão sobre as
tuas aprendizagens.
Penso que é importante trazer argumentos sobre o que as interdisciplinas do
PEAD contribuiram para a poposta desta atividade. Houve diferença entre a
forma que trabalhava esta data comemorativa antes do curso?


Para qualificar este processo, paralelamente a esta proposta avaliativa das alunas do PEAD, foram propostas formações à equipe de tutores com o intuito de refletir sobre construção desta interlocução com os futuros educadores. Tais discussões proporcionaram a criação de um roteiro orientador das intervenções nas produções das alunas, especialmente nos blogs-portfólio, observando os seguintes critérios:

- CLAREZA TEXTUAL - muitas postagens são relacionadas com as atividades das interdisciplinas do PEAD, porém muitas vezes partem do pressuposto de que a atividade realizada é conhecida por todos e, portanto, não a apresentam, não deixam claro o que foi realizado;

- FOCO NA APRENDIZAGEM - existe uma preocupação em mostrar (nos blogs) o que foi feito, a aplicação de uma atividade com os alunos. Todavia é fundamental a reflexão sobre a ação, sobre as aprendizagens de cada aluna-professora;

- EMBASAMENTO - compreendendo os três elementos que seguem:

1. Evidências - ações concretas que demonstram as aprendizagens da aluna.

2. Argumentos - posicionamento. Qual a aprendizagem identificada? Qual sua relevância e relações com os estudos realizados no PEAD?

3. Referências - identificar as ideias de outros autores. De onde vem esta ideia que utilizo para sustentar, argumentar, justificar, contrapor meu pensar?

Ao compreender que a principal característica dos blogs-portfólio é sua abertura ao diálogo, torna-se fundamental destacar que são espaços de trocas e reflexões sobre os processos de aprender em permanente construção, e não meros repositórios de relatos de experiência. Cada blog-portfólio se constitui como um artefato que, ao fundir processo e produto, evidencia as construções e aprendizagens em processo. Neles, a participação dos professores e tutores tem como principal função provocar, motivar e mediar o processo reflexivo na medida em que:

Espera-se que a vivência compartilhada com os professores formadores e com os colegas em formação contribua para que cada um encontre a sua forma de trabalhar e tenha autonomia para dirigir situações de aprendizagem para si e para os outros. (...) No cerne desta proposta está a apropriação e o direcionamento do próprio desenvolvimento profissional. (CARVALHO e PORTO, 2005, p. 17)

Inicialmente, as intervenções, realizadas por meio de comentários deixados nas postagens, buscam superar a ideia hegemônica de avaliação baseada no binômio certo $\mathrm{X}$ errado. Paulatinamente, as intervenções dos tutores e professores tornam-se trocas valiosas para a construção dos conhecimentos. Os comentários passam a ser entendidos como um outro olhar sobre o registro, deixando de ser encarados como sentenças e julgamentos. Passam a ser vistos como uma forma de colaboração e diálogo, tal como se percebe nesta postagem feita pela aluna após uma intervenção da tutoria.

ALUNA: [...] gostaria de registrar dois pontos importantíssimos dentro de minhas aprendizagens durante o curso. O primeiro: a importância da troca, do diálogo durante o processo de aprendizagem, da interação, e que necessariamente não precisa ser durante um curso, mas no dia a dia, já que conhecimentos são construídos durante toda nossa existência, mas me refiro ao curso por fazer parte desse momento de minha vida. É impressionante o que os comentários enriquecem, motivam meu desejo de ler, de aprender, e querer ir além do que já construí. (18 jun. 2010) 


\section{(Re) significando a prática da avaliação}

Pode parecer fácil dizer que precisamos romper com a dicotomia existente entre critérios de certo e de errado respectivamente, porém este movimento traz algumas dúvidas: é possível pensar além de uma classificação certo/errado? Conseguimos fugir destas categorias? Que outras categorias poderemos usar?

A adoção dos portfólio de aprendizagens vincula a avaliação ao trabalho pedagógico, na medida em que todos participam e colaboram na tomada de decisões, em vez de apenas cumprir prescrições hierarquizadas do professor e da escola. (VILLAS BOAS, 2004). Assim, ele constitui mais um elemento para a avaliação processual que articula e agrega as aprendizagens relacionadas às diversas áreas de conhecimento que compõem o currículo do curso.

O blog-portfólio compreende o registro individual das aprendizagens consideradas significativas pelas próprias alunas, acompanhadas das evidências e argumentos que as caracterizam como tal. Estes registros, que deveriam ser realizados regularmente ao longo de cada semestre, constituem uma avaliação processual que promove um constante diálogo entre alunas, tutores, professores e conhecimentos. Neles, as intervenções feitas em comentários às postagens objetivam provocar e aprofundar as reflexões.

Assim, a avaliação torna-se um fazer constante e não um momento específico deixado para o final dos processos de ensino e aprendizagem ou dos tempos formais destinados para estes. A exigência da regularidade semanal dos registros, constitui uma forma de garantir a qualidade da avaliação no sentido da inclusão e do acesso contínuo de todos a todos os conhecimentos. (FREITAS, 2009)

Segundo Anastasiou (2003, p. 16):

[...] a aprendizagem exige a compreensão e apreensão do conteúdo pelo aluno, é essencial a construção de um conjunto relacional, de uma rede, de um sistema, onde o novo conhecimento apreendido pelo aluno amplia ou modifica o sistema inicial, a cada contato.

Quando isso ocorre, a visão sincrética, inicial, caótica e não elaborada, que o aluno trazia inicialmente, pode ser superada e re-elaborada numa síntese qualitativamente superior.

Assim, ao final de cada semestre, as alunas utilizam seus registros dos blogsportfólio para construir uma Síntese das Aprendizagens, tendo como base questões orientadoras elaboradas pelos professores das interdisciplinas que compõem cada eixo. Ao promover uma releitura dos registros postados ao longo do semestre, abre-se a possibilidade de a aluna ampliar ou modificar suas reflexões anteriores. Esta produção escrita não é uma mera cópia daquilo que foi escrito e compartilhado no blog-portfólio, mas constitui uma construção qualitativamente superior.

Tanto nas construções ao longo do semestre, quanto nas sínteses a participação dos professores e tutores tem como principal função provocar, motivar e mediar o processo reflexivo na medida em que o portfólio constitui-se como "[...] um instrumento de estimulação do pensamento reflexivo, facilitando oportunidades para documentar, registrar e estruturar os procedimentos e a própria aprendizagem" (VIEIRA, 2002, p. 150).

É importante destacar que, segundo Araújo (2007, p. 3), a gênese da construção dos portfólios está "[...] na interação com os outros, na ação externa, o que não dispensa o processo de auto-implicação de quem o produz. Ou seja, na produção do portfolio 
reflexivo, dá-se a relação dialética entre o inter e o intrapessoal”. Assim, as intervenções iniciais, buscam superar a ideia hegemônica de avaliação baseada no binômio certo $\mathrm{X}$ errado. Percebeu-se que ainda se faz muito presente em nós a dificuldade de lidar com o erro, baseado no pressuposto de que ele deve ser evitado, escondido e eliminado. Este medo de errar aparece em justificativas da ausência de postagens, afinal, a grande dificuldade na escrita neste espaço público - passível de avaliação e do olhar do outro reside no medo de estar errada.

\section{Considerações finais}

Segundo Paulo Freire (1996, p. 22), “a reflexão crítica sobre a prática se torna uma exigência da relação Teoria/Prática sem a qual a teoria pode ir virando blábláblá e a prática, ativismo". Nesse contexto, a utilização dos blogs, como espaço para construção dos Portfólios de Aprendizagens, buscou a integração das ferramentas tecnológicas e didáticas às teorias, sendo marcada pelos registros reflexivos do aprofundamento conceitual e teórico realizado a partir do curso e suas relações com as práticas docentes das alunas.

A prática de construção dos portfólios de aprendizagens, conforme propõem os estudos de Vieira (2002), Carvalho e Porto (2005), Villas Boas (2005) e Araújo (2007), objetiva o desenvolvimento de profissionais reflexivos, que compreendem seu processo de formação como algo permanente. Tendo como premissa uma concepção de Educação que acredita que a aprendizagem não é mera transferência, mas um processo construído continuamente nas relações com os outros e com o meio. A utilização dos portfólios de aprendizagem na formação de professores "contribui para que a aprendizagem não seja um momento isolado, proposto somente pelo formador, mas, sim, um evento colaborativo" (CARVALHO e PORTO, 2005, p. 57).

Tal como apresentado noutros estudos em contextos semelhantes, foi possível concluir que o portfólio de aprendizagens não pode ser usado como único instrumento de avaliação. (VILLAS BOAS, 2005). Portanto, no desenvolvimento desta proposta buscou-se colocar a avaliação como um componente importante e também resultante dos processos de ensino e aprendizagem, se fazendo presente durante todo o processo de aprender.

Nesse sentido, a análise do trabalho com os blogs-portfólio, revelou que esta prática é um excelente suporte para a construção e desenvolvimento de uma concepção de avaliação participativa e formativa, na qual "todos são avaliados e todos avaliam. Cria-se, assim, a cultura avaliativa da escola, baseada na parceria, no respeito mútuo, na responsabilidade, na seriedade e no rigor." (VILLAS BOAS, 2004, p.30). Neste processo as intervenções dos professores e tutores são fundamentais para a construção da autoria das alunas. Cabe ressaltar que esta relação de parceria que se estabelece toma como referência as singularidades de cada aluna e, portanto, ainda que as intervenções da tutoria sejam qualificadas e preocupadas com a produção das alunas, cada uma se constitui, enquanto autora, em níveis diferentes.

\section{Referências}

ANASTASIOU, Léa das Graças Camargos. Ensinar, aprender, apreender e processos de ensinagem. In: ANASTASIOU, Léa das Graças Camargos; ALVES, 
Leonir Pessate (orgs.). Processos de Ensinagem na Universidade: pressupostos para as estratégias de trabalho em aula. Joinville: UNIVILLE, 2003, p. $12-18$.

ARAÚJO, Elaine Sampaio. O uso do portfólio reflexivo na perspectiva histórico cultural. Trabalho apresentado na $30^{\mathrm{a}}$ Reunião Anual da ANPEd, no GT Formação de Professores. Caxambu (MG): 2007. Disponível em: <http://www.anped.org.br/re unioes/30ra/trabalhos/GT08-3310--Int.pdf>. Acesso em: 08 Ago. 2010.

BRASIL. Resolução CNE/CP 1, de 18 de fevereiro de 2002. Disponível em: <http://portal.mec.gov.br/cne/arquivos/pdf/CP012002.pdf>. Acesso em: 14 mar 2010.

BRASIL. Parecer CNE/CP 9/2001, de 08 de maio de 2001. Disponível em: $<$ http://portal.mec.gov.br/cne/arquivos/pdf/009.pdf>. Acesso em: 14 mar 2010.

CARVALHO, Marie Jane Soares. PORTO, Leonardo. Portfólio Educacional: Proposta Alternativa de Avaliação - Guia Didático. Porto Alegre: Editora da UFRGS, 2005.

FREIRE, Paulo. Pedagogia da Autonomia: saberes necessários à prática educativa. São Paulo: Paz e Terra, 1996.

FREITAS, Luiz Carlos de. SORDI, Maria Regina Lemes de. MALAVASI, Maria Marcia Sigrist. FREITAS, Helena Costa Lopes de. Avaliação Educacional: caminhando pela contramão. Petrópolis: Vozes, 2009.

NEVADO, Rosane Aragón de. CARVALHO, Marie Jane Soares. MENEZES, Crediné Silva de. Educação a distância mediada pela internet: uma abordagem interdisciplinar na formação de professores em serviço. In: (Org.). Aprendizagem em rede na Educação a Distância: Estudos e Recursos para Formação de Professores. Porto Alegre: RICARDO LENZ, 2007, p. 17-33.

SANTOS, Edméa Oliveira. Ambientes virtuais de Aprendizagem: por autorias livres, plurais e gratuitas. In: FAEBA, v.12, no. 18, 2003. Disponível em: < http://www. comunidadesvirtuais.pro.br/hipertexto/home/ava.pdf>. Acesso em 23 set. 2010.

SILVA, M. Docência Interativa presencial e online In: VALENTINI,Carla Beatris; SCHELMMER, Eliane. (Org.). Aprendizagem em ambientes virtuais: compartilhando idéias e construindo cenários. Caxias do Sul: EDUCS, 2005, p.193-202.

VIEIRA, Vania M. O. Portfólio: Uma proposta de avaliação como reconstrução do processo de aprendizagem. In: Revista: Psicologia Escolar e Educacional. ABRAPEE. Vol. $6 \mathrm{n}^{\circ} 2$ junho/dezembro 2002, p. 149-153.

VILLAS BOAS, Benigna Maria de Freitas. O portfólio no curso de pedagogia: ampliando o diálogo entre professor e aluno. Educação e Sociedade, Campinas, vol. 26, n90, p. 291-306, Janeiro/Abril 2005. Disponível em: $<$ http://www.scielo.br/scielo.php?script=sci_arttext\&pid=S0101-73302005000100013>. Acesso: 21 mar 2010

VILLAS BOAS, Benigna Maria de Freitas. Portfólio, avaliação e trabalho pedagógico. Campinas: Papirus, 2004.

WARSCHAUER, Mark. Tecnologia e Inclusão Social: A Exclusão Digital em Debate. São Paulo: Editora Senac São Paulo, 2006.

WARSCHAUER Cecília. A roda e o registro: uma parceria entre professor, alunos e conhecimento. Rio de Janeiro: Paz e Terra, 1993.

ZILIO, Cátia. Ganhando mundo: A aula que escapa das paredes do tempo e do espaço. UNIrevista, São Leopoldo, UNISINOS, Vol. 1, n²., p.1-9, abril 2006. Disponível em: <http://www.unirevista.unisinos.br/_pdf/UNIrev_Zilio.pdf> 